\title{
Zen meets medicine
}

$\mathrm{P}$ hysician as theologian? It just might be the next dimension of modern medicine, according to proponents of "spiritual health care."

As defined in the province of Manitoba's recently unveiled spiritual health care plan - the country's first - it's not necessarily a religious concept. But it is "therapeutic," states the plan, Health and the Human Spirit: Shaping the Direction of Spiritual Health Care in Manitoba (www.gov.mb.ca/healthy living/mh/hhs.html). Spiritual health care "closes the gap between patient and provider by focusing on the quest for self-awareness as an essential encompassing aspect of healing and wellness."

"The comprehensive spiritual health care field does not begin with a problem that must be solved, but rather employs a therapeutic means of listening which focuses on holistic health and wellbeing," the plan adds, noting that spiritual health care is "not an attempt to impose, intervene or control."

So enthused is Manitoba by the notion that they have already hired seven spiritual health care coordinators, at a cost of $\$ 625000$, to work with physicians, patients and their families to bring the practice of improving spiritual well-being into the forefront of all levels of health care.

"The reason why we moved forward with the strategic plan is that we looked at the practice of health care and realized that what we actually had to do was focus on the entire person which is the body, the mind, relationships and spirituality at every age and every experience," says Healthy Living, Seniors and Consumer Affairs Minister Jim Rondeau. "It's a view of looking at spirituality and support for the person in their journey through the health care system."

Patients are invariably in a state of anxiety, whether as a result of awaiting a test, undergoing a procedure, preparing for prenatal care or facing end-of-life care, Rondeau adds. "There is always a

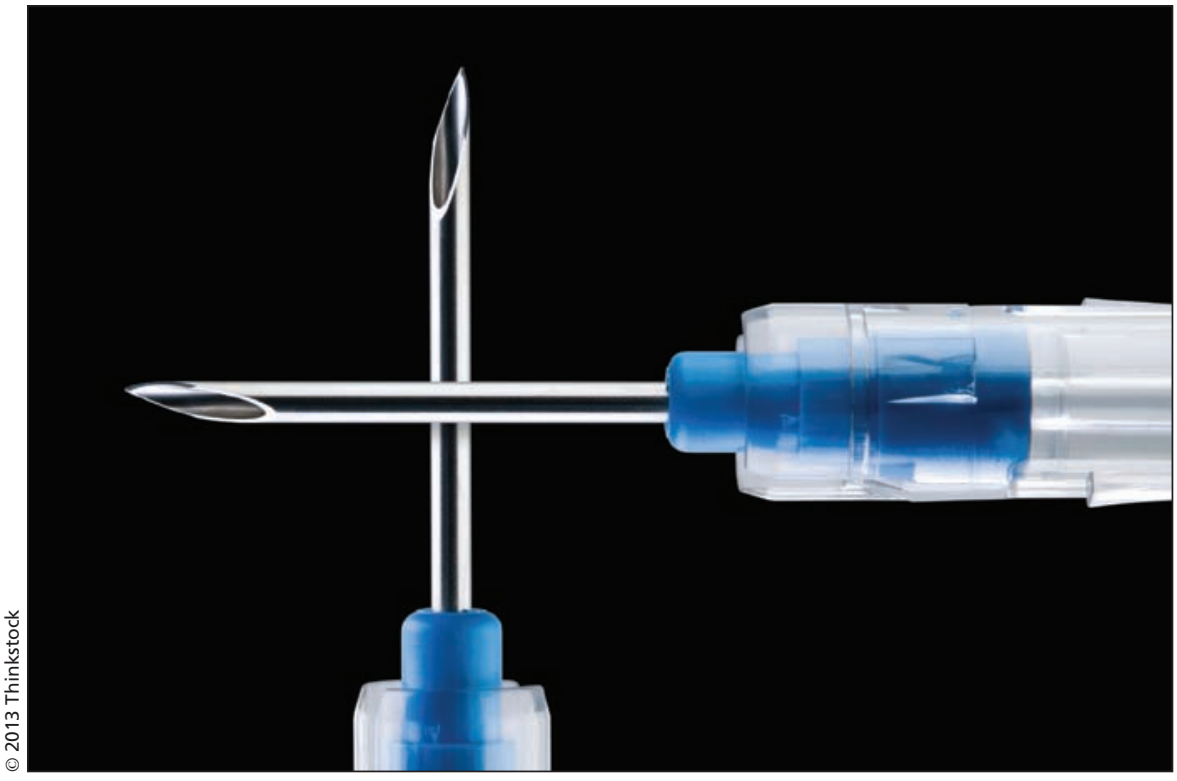

Understanding disease and the "human experience of illness" should go hand in hand, spiritual health care advocates argue.

deal of stress and anxiety regardless of how good the professionals are, the doctors are and the nurses are."

The anxiety elicits a physiological and emotional response from the patient, which health practitioners can help alleviate by addressing spiritual needs, Rondeau says. "If you're anxious and you're nervous and you're not sleeping well, guess what happens physiologically to you? You don't heal as well. There is documented evidence that when you're supported and comfortable and you feel well emotionally, it helps your physical healing."

Rondeau expects the end result will be improved health outcomes and reduced costs to the system. "I believe healing will be faster, I think there will be less stress with families and loved ones and I think that what will happen is people will be supported in their healing journey better, which thus has better health outcomes," he says. "Personally, I think that whatever support we can give you that will get you to sleep and eat right and be less anxious - you won't be in recovery as much. That will save money, but more importantly your journey will be better."
While many might perceive spiritual health care as inextricably linked to religion, proponents say it is more accurately related to a patient's overall spiritual well-being. "It can be religious - it doesn't have to be religious," says Doug Kellough, president of the Canadian Association for Spiritual Care, a nongovernmental multifaith organization which provides training for spiritual health care providers. "If people understand that spirituality has to do with who they see themselves to be, what kind of support they have either through family or friends or community, what kind of hopes and dreams they have and the meaning that they associate in life - that helps people to see where the difference lies."

It's important to take a broad view of spiritual health care, adds Karen Toole, Manitoba's provincial spiritual care coordinator in the Healthy Living, Seniors and Consumer Affairs Ministry. "The presumption that it is exclusively religious care will come from people who still associate the word spiritual exclusively with religious understandings. But then you'll have other people who have a much different understand- 
ing of spirituality and we help them articulate what that is when they are facing a crisis."

That's not to say that spiritual health care precludes a religious element, she adds. "It matters in the sense of respect and dignity. If a person wants religious rights and religious rituals that they believe have a positive effect on their health care journey we provide those. But if they don't come from that background and they are looking for something that is not expressed that way, we help them determine what that would be."

By taking a broader approach, Rondeau says, health care practitioners can provide spiritual health care for all patients. "It's all individual. It's not based on a religion or a faith or a belief. This is good for First Nations people, agnostics. It's good for anybody, because whether you're religious or you're not, spirituality is an individual thing."

As currently envisioned by Manitoba, health care providers would address spiritual concerns with patients undergoing any level of treatment by simply inquiring about the patient's level of spirituality and then refer him to a chaplain or spiritual health care coordinator if and as needed.

Kellough believes specially trained personnel are critical. Spiritual health care practitioners have undergone years of training, similar to doctors and nurses, which prepares them to deal with patients having a range of spiritual beliefs, he says. "I'm not sure that a doctor has the time or the energy or necessarily the inclination to add that much to their training."

While physicians are experts at understanding diseases, spiritual health care practitioners understand the "human experience of illness - the anxiety, the fear, even the dread," he says. "Allowing people to be able to speak about that and taking the time with them to listen, to be emotionally present, to be supportive, even just to talk about how they are feeling and without judgment supporting them. Those are important factors in helping people to face what they are facing."

"Today I spoke to a person who has been struggling after a heart transplant and so I asked what gives them the motivation to keep going and for that person it was family and we talked about how that helps. That's not religion but it's certainly part of spirituality," he adds.

In aid of its foray into spiritual health care, Manitoba has unveiled a province-wide spiritual health care education course that is available to physicians, volunteers, religious leaders, spiritual leaders and Aboriginal leaders. "What it does is talk about the core competencies for spiritual health care practitioners. Nothing precludes doctors from taking it, because you want to provide people with the tools they need to support individuals," Rondeau says.

Toole notes there has traditionally been little in the way of formal education to prepare medical graduates to provide spiritual health care but a growing number of physicians are embracing the notion in an effort to get a better understanding of patient needs. "Regular physicians can do this if they are able and interested to make that part of their practice and some are very, very good at it and some are coming onboard to it with more awareness," she says.

"There is certainly a vast realm of study related to spirituality, as to whether physicians and medical students want to open their door that's not something we can directly control but it's certainly something we can encourage," Toole adds.

Rondeau hopes more provinces will follow Manitoba's lead and to that end, the province raised the subject at a meeting of provincial health ministers in late September. "I hear from doctors and practitioners that they are interested in this, they want to experience this, they'll take the training as part of their ongoing professional development and then what will happen is we'll learn and continue to go forward."

"You take the eager people who want to apply it, you give them the opportunities to learn and develop the system, then you learn from that journey and you continue to expand the circle," Rondeau adds. - Adam Miller, CMAJ

CMAJ 2013. DOI:10.1503/cmaj.109-4314

Editor's note: First of a two-part series.

Next: Incorporating theology into medical education 